\title{
Mortality in a large community-based cohort of inner-city residents in Vancouver, Canada
}

\author{
Gregory D. Deans MD MHSc, Jesse D. Raffa MSc, Calvin Lai MSc, Benedikt Fischer PhD, Mel Krajden MD, \\ Janaki Amin MPH, Scott R. Walter MBiostat, Gregory J. Dore MBBS PhD, Jason Grebely PhD, \\ Mark W. Tyndall MD ScD
}

\section{Abstract}

Background: The Downtown Eastside is a robust and densely populated neighbourhood in Vancouver, Canada, that is characterized by low-income housing and drug use and a high prevalence of HIV infection. We evaluated mortality and excess mortality among the broader community of individuals living in this neighbourhood.

Methods: The Community Health and Safety Evaluation is a community-based study of inner-city residents in the Downtown Eastside who were recruited in 2003 and 2004. Participants' data were linked with data in provincial virology and mortality databases retrospectively and prospectively for the period 1991-2009. Mortality and standardized mortality ratios (SMRs) were calculated for the period 2003-2009 to compare death rates in the study population with rates in the population of Vancouver.

Results: Among 2913 participants, 374 deaths occurred, for an all-cause mortality of 223 per 10000 person-years (95\% confidence interval [Cl] 201-247 per 10000 person-years). Compared with the population of Vancouver, significant excess mortality was observed in the study population (SMR 7.1, 95\% Cl 6.4-7.9). Excess mortality was higher among women (SMR 15.4, 95\% Cl 12.818.5) than among men (SMR 5.8, 95\% Cl 5.1-6.6). Although crude mortality increased with age, excess mortality was greatest among participants less than 35 years old (SMR 13.2, 95\% Cl 9.4-18.5) and those 35-39 years old (SMR 13.3, 95\% Cl 10.3-17.1). Excess risk was also elevated among participants with hepatitis C virus (HCV), HIV and HCV/HIV infection, with SMRs of 5.9 (95\% Cl 4.9-7.1), 19.2 (95\% Cl 12.8-28.9) and 23.0 (95\% Cl 19.3-27.4), respectively.

Interpretation: Our study showed high mortality in this inner-city population, particularly when compared with the general population of Vancouver. Excess mortality was highest among women, younger participants and those infected with either HCV or HIV or both.

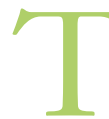
he Downtown Eastside is an inner-city neighbourhood in Vancouver, Canada, with a population of more than 16000 , including an estimated 4700 who are injection drug users. ${ }^{1,2}$ Rising rates of fatal drug overdose and HIV infection in this neighbourhood prompted the declaration of a public health emergency in 1997., Despite intensive study, improvements in social services and the implementation of several effective public health interventions, ${ }^{5,6}$ the impact on health outcomes and overall mortality at a community level is uncertain. Surveillance of mortality in inner-city populations is crucial to document disease trends and implement interventions that can have the biggest health impact.

Most studies of mortality in the Downtown Eastside have examined cohorts of injection drug users, ${ }^{2,-9}$ which may not be generalizable to the broader community. Studies examining excess mortality have largely focused on all-cause mortality in specific populations, such as women ${ }^{7}$ and young injection drug users, ${ }^{2}$ or have included surrounding neighbourhoods with higher socioeconomic status. ${ }^{10} \mathrm{We}$ conducted this study to evaluate the mortality and excess mortality for all-cause and cause-specific deaths during the period 2003-2009 among residents in this inner-city neighbourhood.

\section{Methods}

\section{Study population}

The Community Health and Safety Evaluation (CHASE) cohort was designed to evaluate the uptake of health services and health outcomes in Vancouver's Downtown Eastside. To collect a broad sample of residents in this community, facility-based sampling ${ }^{11}$ was used and venues for recruitment

Competing interests: See end of article.

This article has been peer reviewed.

Correspondence to: Gregory Deans, gregory.deans@fraserhealth.ca CMAJ Open 2013.DOI:10.9778/cmajo.20130002 
were selected based on census tract data. ${ }^{12}$ People were informed of the project through community-based agency staff, postings in local agencies, door-to-door initiatives and word of mouth. Surveys were administered in a variety of settings, including 10 community-based agencies, 2 community health clinics, 117 single-room occupancy hotels and social housing buildings, and a large space that operates as a needleexchange site. All residents included in the study had their names and personal health numbers verified through the British Columbia Ministry of Health database to facilitate linkage with hepatitis $\mathrm{C}$ virus and HIV test results and with health indicator databases.

Between January 2003 and December 2004, a total of 2913 participants received $\$ 10$ to complete a one-time, intervieweradministered survey (to collect information on demographics, health services utilization and drug use in the 6 months before the survey) and consented to have their data linked to health databases by name, date of birth and provincial health number. This study was approved by the University of British Columbia Providence Health Care Research Ethics Board.

\section{Data collection}

Participants' data were linked with data in provincial virology and mortality databases retrospectively and prospectively for the period 1991-2009. Linkage was performed using the participants' provincial health number or, for those with no match, their name and date of birth. ${ }^{12}$ Results of antibody testing for hepatitis C virus (HCV) and HIV from 1991 to 2009 were obtained through database linkages with the British Columbia Centre for Disease Control and the University of British Columbia Virology Department (responsible for all $\mathrm{HCV}$ and HIV testing in the province).

For deaths from 2003 to 2009, the underlying causes of death were obtained from the BC Vital Statistics database, which captures information on all deaths in the province. Causes of death were classified according to the International Statistical Classification of Diseases and Related Health Problems, 10th revision (ICD-10) codes. Causes of death were grouped according to ICD-10 chapter headings as well as by drug-related, HIV-related and liver-related causes. Drug-related deaths comprised mental and behavioural disorders due to psychoactive substance use (ICD-10 codes F11-16 and F19), accidental poisoning by drugs (X40-44), suicide by drugs (X60-64), assault by drugs and medicaments (X85), poisoning by drugs or medicaments undetermined if accidental or intentional (Y10-14), and adverse effects of drugs and medicaments (Y40-574, Y577-79, Y598 and Y880). HIV-related deaths were defined as any death with an HIVrelated ICD-10 code (B20-24), whereas liver-related deaths comprised deaths from viral hepatitis (B15-19), liver cancer (C22), alcoholic liver disease (K70) or nonalcoholic liver disease (K71-77).

\section{Outcome measures}

The primary outcome measure was mortality. We determined both overall and cause-specific mortality and expressed them as rates of death and standardized mortality ratios (SMRs).

\section{Statistical analysis}

Participants who had linked data for HCV and HIV test results were divided into 4 mutually exclusive strata (HCV positive/HIV negative; HIV positive/HCV negative; $\mathrm{HCV}$ and HIV positive; and HCV and HIV negative) for stratified analyses. The HCV positive/HIV negative group included individuals with positive $\mathrm{HCV}$ test results and negative or unknown HIV results. The HIV positive/HCV negative group included those with positive HIV test results and negative or unknown HCV results. Participants with unknown test results were included in these groups because they had characteristics similar to those who tested negative (unpublished data). Causes of death were examined overall and among these

\section{Table 1: Characteristics of 2913 participants in a community- based cohort in the inner city of Vancouver}

\begin{tabular}{cc}
\hline & No. (\%) of participants* \\
Characteristic & $n=2913$
\end{tabular}

\begin{tabular}{|c|c|}
\hline Age, $y r$, mean $\pm S D$ & $42.5 \pm 10.1$ \\
\hline Female sex & $845(29.0)$ \\
\hline Aboriginal ethnicity & $895(30.7)$ \\
\hline Unstable housing $†$ & $1801(61.8)$ \\
\hline Jail time† & $610(20.9)$ \\
\hline Alcohol use† & $1490(51.2)$ \\
\hline Drug use (injection or noninjection) $\dagger$ & $2337(80.2)$ \\
\hline Injection drug use $†$ & $1114(38.2)$ \\
\hline Overdose† & $205 \quad(7.0)$ \\
\hline Methadone treatment $†$ & $561(19.3)$ \\
\hline \multicolumn{2}{|l|}{ HCV infection $\ddagger$} \\
\hline Yes & $1533(52.6)$ \\
\hline No & $872(29.9)$ \\
\hline Unknown & $508(17.4)$ \\
\hline \multicolumn{2}{|l|}{ HIV infection $\ddagger$} \\
\hline Yes & $535(18.4)$ \\
\hline No & $1735(59.6)$ \\
\hline Unknown & $643(22.1)$ \\
\hline \multicolumn{2}{|l|}{ HCV and HIV infection stratał } \\
\hline $\mathrm{HCV}+/ \mathrm{HIV}-\S$ & $1068(36.7)$ \\
\hline $\mathrm{HCV}-/ \mathrm{HIV}+\boldsymbol{\eta}$ & $70 \quad(2.4)$ \\
\hline $\mathrm{HCV}+/ \mathrm{HIV}+$ & $465(16.0)$ \\
\hline HCV-/HIV- & $693(23.8)$ \\
\hline Unknown** & $617(21.2)$ \\
\hline
\end{tabular}

Note: $\mathrm{HCV}=$ hepatitis $\mathrm{C}$ virus, $\mathrm{SD}=$ standard deviation

*Unless stated otherwise.

tIn the 6 months before the survey (self-reported).

łBased on all linked laboratory test results (1991-2009). Characteristics of participants by HCV/HIV infection strata are shown in Appendix 1 (available at www.cmajopen.ca/content/1/2/E68/suppl/DC1).

SIncludes participants whose HCV result was positive and whose HIV status was either negative or unknown.

qIncludes participants whose HIV result was positive and whose HCV status was either negative or unknown.

**Includes participants whose HCV status and HIV status were both unknown; it also includes participants whose status was unknown for either HCV or HIV and who had a negative HIV or HCV result, respectively. 
strata. We calculated mortality using person-time methods. Person-years at risk were calculated for each participant as the time from the date of the survey questionnaire to the date of death or Dec. 31, 2009, whichever came first.

We calculated SMRs to compare death rates in the study population with rates in the population of Vancouver (specifically, the Health Service Delivery Area of Vancouver, population 590 240) for each cause of death. The SMRs were adjusted for sex, 5-year age group and calendar year of death, with the last 2 variables treated as time-dependent covariates. Participants with missing data on date of birth $(0.2 \%, n=7)$ were excluded from SMR analyses. We used the Poisson exact method to calculate $95 \%$ confidence intervals (CIs) for incidence rates and SMRs. Trends in rates from 2003 to 2009 were examined using Poisson regression. We considered $p$ values of less than 0.05 (2-sided test) to be statistically significant. Statistical analyses were performed using R (version 2.15; R Foundation for Statistical Computing, Vienna, Austria) and STATA (version 10.1; StataCorp, College Station, Texas).

\section{Results}

Characteristics of the 2913 participants recruited into the CHASE cohort in 2003-2004 are shown in Table 1. The mean age was 42.5 years, and 845 (29.0\%) were female. Among the participants for whom results of antibody testing for HCV and HIV were available during the linkage period (1991-2009), $63.7 \%(1533 / 2405)$ had HCV infection, $23.6 \%$ (535/2270) had HIV infection, and $21.8 \%(465 / 2130)$ had both. Injection or noninjection drug use in the 6 months before the survey was reported by 2337 (80.2\%) of the participants.

Between January 2003 and December 2009, 374 deaths were reported over 16778 person-years of observation, for an all-cause mortality of 223 per 10000 person-years (95\% CI
201-247 per 10000 person-years) (Table 2). According to $\mathrm{HCV}$ and HIV status, the rate of death per 10000 personyears was 167 (95\% CI 138-203) among participants with HCV infection alone, 641 (95\% CI 426-964) among those with HIV alone, 515 (95\% CI 432-613) among those with HCV/HIV co-infection and 107 (95\% CI 79-143) among those with neither HCV nor HIV infection (Table 3). Compared with the population of Vancouver, significant excess mortality was observed in the study population (SMR 7.1, 95\% CI 6.4-7.9) (Table 2). Significantly higher excess risk was observed among participants with HCV infection (SMR 5.9, 95\% CI 4.9-7.1), HIV infection (SMR 19.2, 95\% CI 12.828.9) and HCV/HIV co-infection (SMR 23.0, 95\% CI 19.327.4) compared with those who had neither HCV nor HIV infection (SMR 3.5, 95\% CI 2.6-4.7) (Table 3).

Causes of death for the whole study population and for subgroups stratified by HCV and HIV status are shown in Tables 2 and 3, respectively (corresponding data for participants classified as having "unknown" status are shown in Appendix 2, available at www.cmajopen.ca/content/1/2 /E68/suppl/DC1). Overall, of the 374 deaths, the most common causes were infection (25.9\%), external causes $(16.6 \%)$, respiratory disease $(11.8 \%)$ and neoplasm $(11.2 \%)$; external causes included accidents, assault and intentional self-harm. Infection-related deaths were predominantly related to HIV/AIDS (80.4\%). Excess mortality related to respiratory disease was due primarily to pneumonia (48.9\% [22/45]) and chronic lower respiratory diseases (31.1\% [14/45]). The highest cause-specific SMRs overall were for "other" causes, infection, respiratory disease, and mental and behavioural disorders; the same 4 causes accounted for much of the greatest excess risk among participants with HCV, HIV and $\mathrm{HCV} / \mathrm{HIV}$ infection as well. Causes of deaths classified as "other" included the ICD-10 code for "other ill-defined and

\begin{tabular}{|c|c|c|c|c|}
\hline Cause of death & ICD-10 codes & $\begin{array}{l}\text { No. of } \\
\text { deaths }\end{array}$ & $\begin{array}{l}\text { Rate per } 10000 \\
\text { person-years }(95 \% \mathrm{Cl})\end{array}$ & $\mathrm{SMR}^{*}(95 \% \mathrm{Cl})$ \\
\hline All & & 374 & $223(201-247)$ & $7.1 \quad(6.4-7.9)$ \\
\hline Infection & A00-B99 & 97 & 58 (47-71) & $20.2(16.5-24.6)$ \\
\hline Neoplasm & C00-D48 & 42 & 25 (18-34) & $2.7 \quad(2.0-3.7)$ \\
\hline Endocrine & E00-90 & 4 & $2 \quad(1-6)$ & $2.4 \quad(0.9-6.3)$ \\
\hline Mental or behavioural & F00-99 & 13 & $8 \quad(4-13)$ & $11.1 \quad(6.4-19.0)$ \\
\hline Nervous system & G00-99 & 8 & $5 \quad(2-10)$ & $7.0 \quad(3.5-14.0)$ \\
\hline Circulatory system & $100-99$ & 41 & 24 (18-33) & $4.1 \quad(3.0-5.5)$ \\
\hline Respiratory system & J00-99 & 44 & 26 (20-35) & $12.1(9.0-16.3)$ \\
\hline Digestive system & K00-93 & 20 & $12 \quad(8-18)$ & $7.3 \quad(4.7-11.3)$ \\
\hline Genitourinary system & N00-99 & 4 & $2 \quad(1-6)$ & $7.3 \quad(2.7-19.4)$ \\
\hline Other† & R00-99 & 39 & $23(17-32)$ & $37.8(27.6-51.7)$ \\
\hline External cause & V00-Y98 & 62 & 37 (39-47) & $6.5 \quad(5.0-8.3)$ \\
\hline \multicolumn{5}{|c|}{$\begin{array}{l}\text { Note: } \mathrm{Cl}=\text { confidence interval; ICD-10 = International Statistical Classification of Diseases and Related Health Problems, 10th revision; SMR = standardized } \\
\text { mortality ratio. } \\
\text { *Reference group was the population of Vancouver. } \\
\text { tIncludes unknown causes of death. }\end{array}$} \\
\hline
\end{tabular}




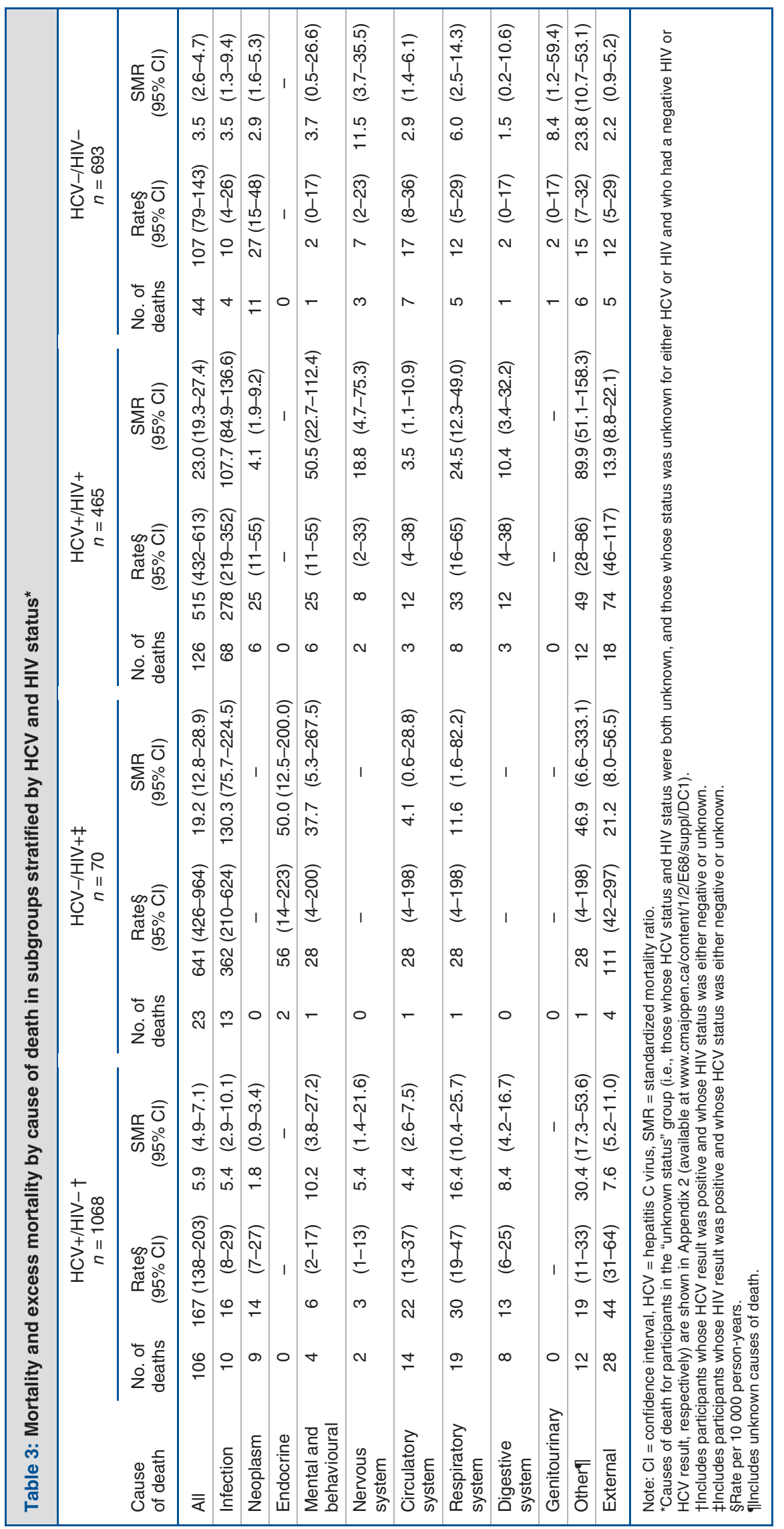


unspecified causes of mortality" $(n=34)$ and deaths with missing data regarding cause of death $(n=6)$.

Mortality and excess mortality related to drug use, liver disease and HIV infection are shown in Tables 4 and 5 and in Appendix 3 (available at www.cmajopen.ca/content/1/2 /E68/suppl/DC1). Overall, 14.2\% of deaths were drug-related (32 deaths [95\% CI 24-41] per 10000 person-years), which represents a considerable excess risk of drug-related mortality (SMR 12.0, 95\% CI 9.1-15.7). Liver-related deaths accounted for $5.9 \%$ of the deaths, for a rate of 13 (95\% CI 9-20) per 10000 person-years (SMR 5.9, 95\% CI 3.9-8.9). The rate of HIV-related deaths was 46 (95\% CI 37-58) per 10000 person-years (SMR 24.9, 95\% CI 20.0-31.1).

Women in the cohort had rates of death similar to those among men (Table 4). However, their excess mortality was significantly higher than the excess mortality among men for all causes (SMR 15.4 [95\% CI 12.8-18.5] v. 5.8 [95\% CI 5.16.6]) and for drug-, liver- and HIV-related deaths (Table 4).

Although crude mortality increased with age, excess mortality was highest among participants less than 35 years old (SMR 13.2, 95\% CI 9.4-18.5) and among those 35-39 years old (SMR 13.3, 95\% CI 10.3-17.1); the corresponding SMRs and $95 \%$ CIs for participants aged 45-49 years and those 50 years and older were 6.0 (4.7-7.6) and 5.3 (4.5-6.3) (Appendix 4, available at www.cmajopen.ca/content/1/2/E68/suppl/DC1). Liver-related mortality also increased with age, but it was associated with a relatively stable excess risk across age groups (Figure 1). In contrast, drug-related mortality and excess mortality tended to peak at age 35-39 years. HIV-related mortality was greatest among those aged 45-49 years, with a secondary peak at age 35-39, but HIV-related SMRs trended downward overall with age. The annual rates of death over the period 2003-2009 did not show a significant linear trend (Figure $2 ; p=0.6$ ).

\section{Interpretation}

This large study of a cohort of inner-city residents in Vancouver, Canada, demonstrated several important findings. Very high rates of death, particularly when compared with rates for the general population of Vancouver, were evident for all-cause and cause-specific mortality. Excess mortality was highest among women, younger participants and participants infected with HCV or HIV or both. Major causes of death included HIV infection, drug-related deaths and unknown causes.

The all-cause mortality was high (223 per 10000 personyears) and was associated with considerable excess mortality compared with the general Vancouver population (SMR 7.1). This ratio is much greater than the SMR of 1.2 reported by the British Columbia Vital Statistics Agency for the local health area that contains the Downtown Eastside; ${ }^{10}$ the difference is likely because the latter includes wealthier neighbourhoods outside the inner city that decrease the observed rates of death. The SMR in the cohort inner-city residents in our study is closer in magnitude to those in populations exclusively composed of injection drug users. Previous studies of mortality among injection drug users reported SMRs of

\begin{tabular}{|c|c|c|c|}
\hline Cause of death & No. of deaths & $\begin{array}{l}\text { Rate per } 10000 \\
\text { person-years }(95 \% \mathrm{Cl})\end{array}$ & SMR† $(95 \% \mathrm{Cl})$ \\
\hline All & 374 & 223 (201-247) & $7.1 \quad(6.4-7.9)$ \\
\hline Men & 263 & $220(195-248)$ & $5.8 \quad(5.1-6.6)$ \\
\hline Women & 111 & 230 (191-277) & $15.4(12.8-18.5)$ \\
\hline Drug-related $\ddagger$ & 53 & 32 (24-41) & $12.0 \quad(9.1-15.7)$ \\
\hline Men & 36 & $30 \quad(22-42)$ & $9.3 \quad(6.7-12.9)$ \\
\hline Women & 17 & $35 \quad(22-57)$ & $30.3(18.8-48.7)$ \\
\hline Liver-related§ & 22 & $13 \quad(9-20)$ & $5.9 \quad(3.9-8.9)$ \\
\hline Men & 15 & $13 \quad(8-21)$ & $4.5 \quad(2.7-7.4)$ \\
\hline Women & 7 & $15 \quad(7-30)$ & $17.9 \quad(8.5-37.6)$ \\
\hline HIV-relatedף & 78 & $46 \quad(37-58)$ & $24.9(20.0-31.1)$ \\
\hline Men & 54 & $45 \quad(35-59)$ & $18.7(14.4-24.5)$ \\
\hline Women & 24 & $50 \quad(33-74)$ & $96.8(64.9-144.5)$ \\
\hline \multicolumn{4}{|c|}{$\begin{array}{l}\text { Note: } \mathrm{Cl}=\text { confidence interval; ICD-10 = International Statistical Classification of Diseases and Related Health Problems, } 10 \text { th revision; SMR = } \\
\text { standardized mortality ratio. } \\
\text { *Causes of death for participants in the "unknown status" group (i.e., those whose HCV status and HIV status were both unknown, and those } \\
\text { whose status was unknown for either HCV or HIV and who had a negative HIV or HCV result, respectively) are shown in Appendix } 3 \text { (available at } \\
\text { www.cmajopen.ca/content/1/2/E68/suppl/DC1). } \\
\text { tReference group was the population of Vancouver. } \\
\text { tDeaths from mental and behavioural disorders due to psychoactive substance use (ICD-10 codes F11-16, F19), accidental poisoning by drugs } \\
\text { (X40-44), suicide by drugs (X60-64), assault by drugs and medicaments (X85), poisoning by drugs or medicaments undetermined if accidental o } \\
\text { intentional (Y10-14), and adverse effects of drugs and medicaments (Y40-574, Y577-79, Y598, Y880). } \\
\text { §Deaths from viral hepatitis (B15-19), liver cancer (C22), alcoholic liver disease (K70) and nonalcoholic liver disease (K71-77). } \\
\text { ๆICD-10 codes B20-24. }\end{array}$} \\
\hline
\end{tabular}




\begin{tabular}{|c|c|c|c|c|c|c|c|c|c|c|c|c|c|}
\hline 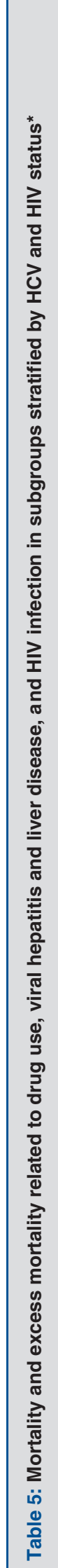 & 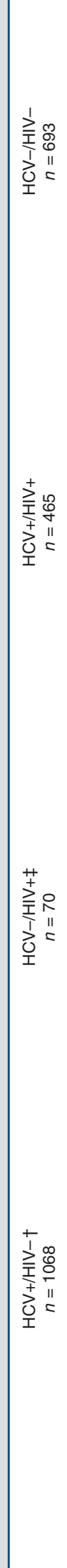 & 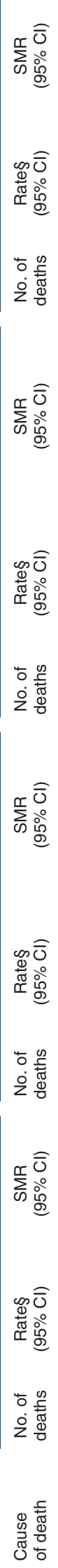 & 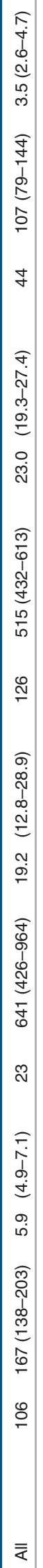 & 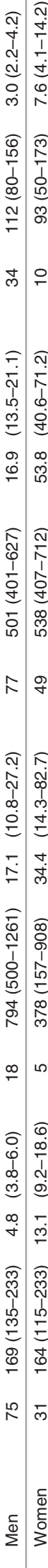 & 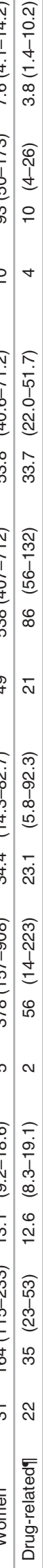 & 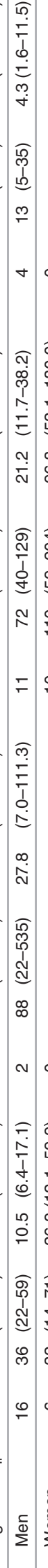 & 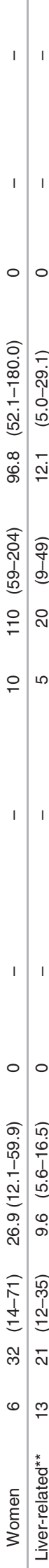 & 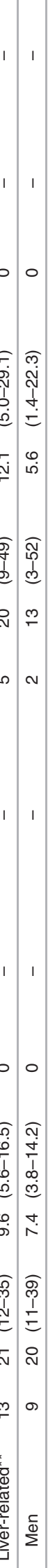 & 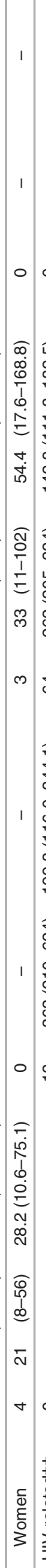 & 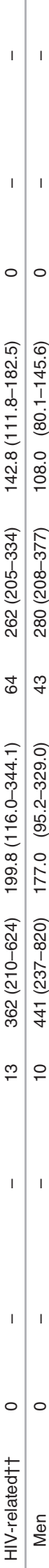 & 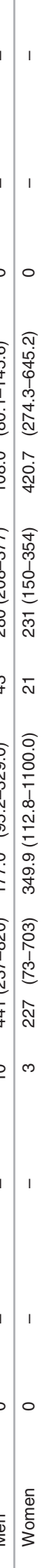 & 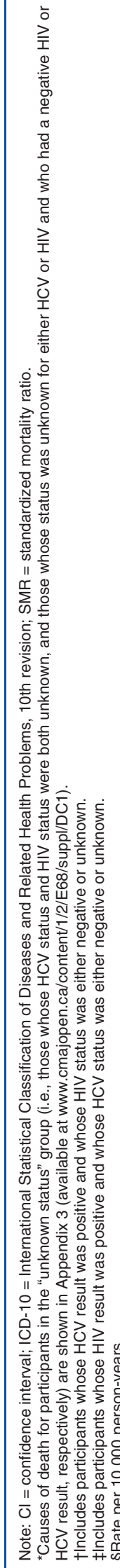 & 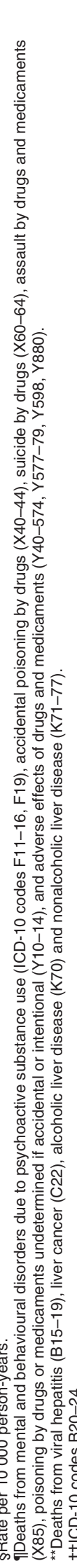 \\
\hline
\end{tabular}


$10-15,{ }^{13,14}$ and excess mortality among users of opiates and opioid substitution therapy has been in the range of 5-13. ${ }^{15-17}$

Most of the causes of death associated with the greatest excess mortality, including infection, "other" causes and mental or behavioural disorders, were consistent with major causes of death identified in other studies..$^{14,15,18-23}$ Of note was the elevated excess mortality related to respiratory disease (primarily pneumonia). A study involving drug users entering treatment in Rome, Italy, reported a similar SMR of 10.2 for respiratoryrelated death. ${ }^{23}$ This is consistent with the observation that pneumonia is an important cause of morbidity and hospital admission among injection drug users. ${ }^{24-26}$

The very high drug-related mortality and excess mortality in our study are consistent with prior findings among injection drug users in Vancouver $^{8}$ and elsewhere. ${ }^{13,15,23,27,28}$ Liver-

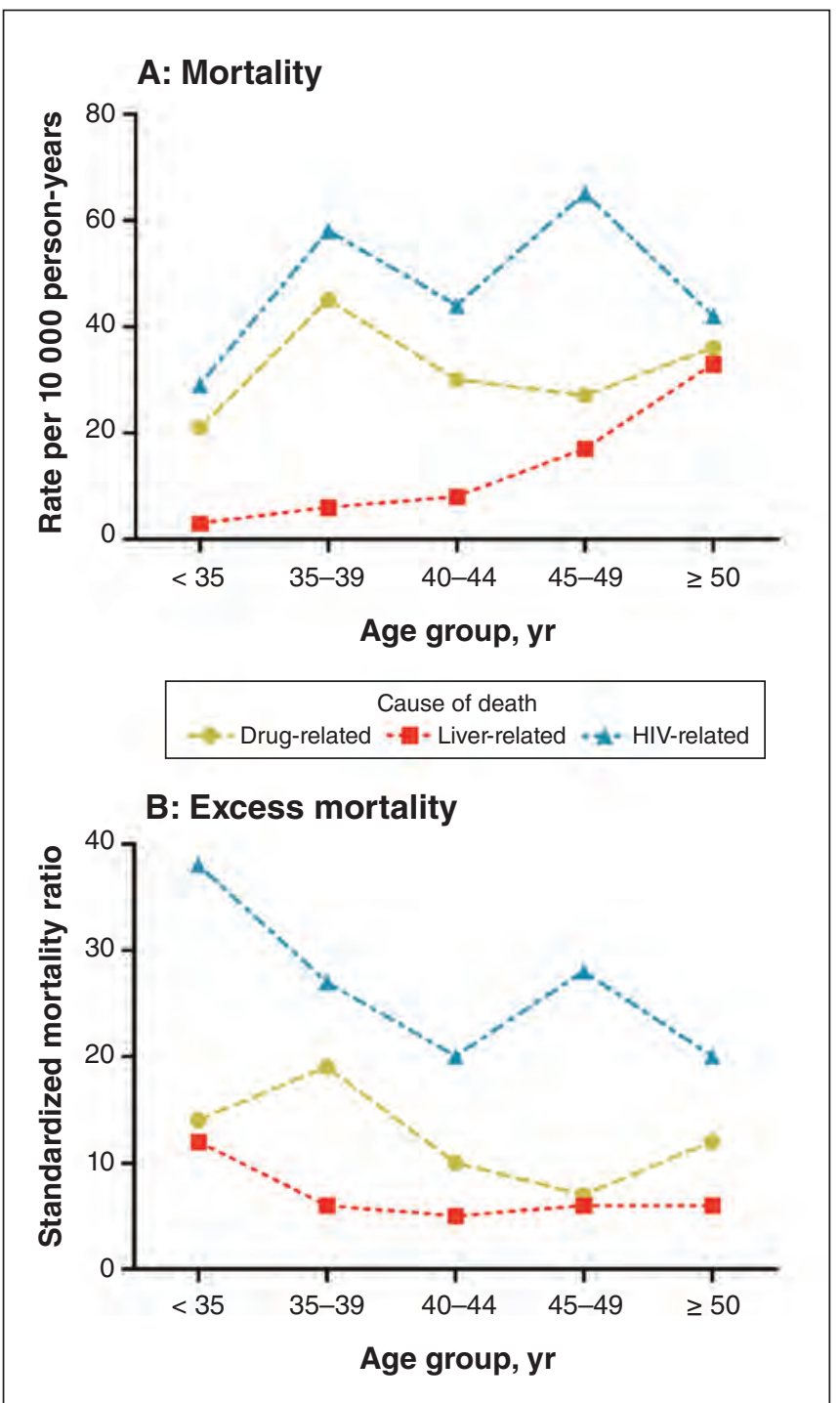

Figure 1: (A) Mortality and (B) excess mortality related to drug use, viral hepatitis and liver disease, and HIV infection among 2913 participants in a large community-based cohort in the inner city of Vancouver, 2003-2009, by age group. Drug-, liver- and HIV-related deaths are defined in Methods. The reference group for the standardized mortality ratios was the population of Vancouver. related mortality, which accounted for $6 \%$ of the deaths, was associated with an SMR of 5.9. Comparatively higher SMRs were reported in studies involving people taking opioid substitution therapy (SMR 17.0) ${ }^{16}$ and among people infected with hepatitis B virus (SMR 10.0) and HCV (SMR 15.8). ${ }^{29}$ Population differences such as age, proportion with viral hepatitis infection and pattern of alcohol use may account for such differences in risk. HIV-related mortality and excess mortality were very high in our study, particularly among participants known to have HIV infection, among whom 77 (51.7\%) of 149 deaths were HIV-related. In studies involving injection drug users, deaths caused by HIV/AIDS accounted for 34\%$38 \%$ of deaths among HIV-infected people. ${ }^{8,14}$

Sex-related differences were evident in the all-cause mortality results: although men and women had similar rates of death, women had a significantly higher excess mortality (SMR 15.4 v. 5.8 for men). SMRs for drug-, liver- and HIVrelated deaths followed similar patterns. In a meta-analysis of mortality among opioid users, men had higher crude mortality rates than women, but women had higher SMRs. ${ }^{18} \mathrm{~A}$ similar pattern in the SMRs for all-cause mortality was observed in a cohort of Vancouver injection drug users., ${ }^{2,7}$ The higher excess mortality among women likely reflects the fact that women in the general population tend to have a lower mortality than men for many major causes of death.

The increase in crude mortality from the youngest group to the oldest is consistent with expected increases in diseases of aging, including malignant diseases and cardiovascular diseases. The lower excess mortality among older participants could be explained by concurrent increases in these agerelated conditions in the general population and by survivorship bias. Liver-related mortality increased with age, which has been observed previously in the HCV-infected subset of this cohort. ${ }^{30}$ Among younger inner-city residents, liverrelated deaths contributed minimally to mortality, whereas among people aged 50 years or older, the rate of liver-related deaths was similar to the drug- and HIV-related rates.

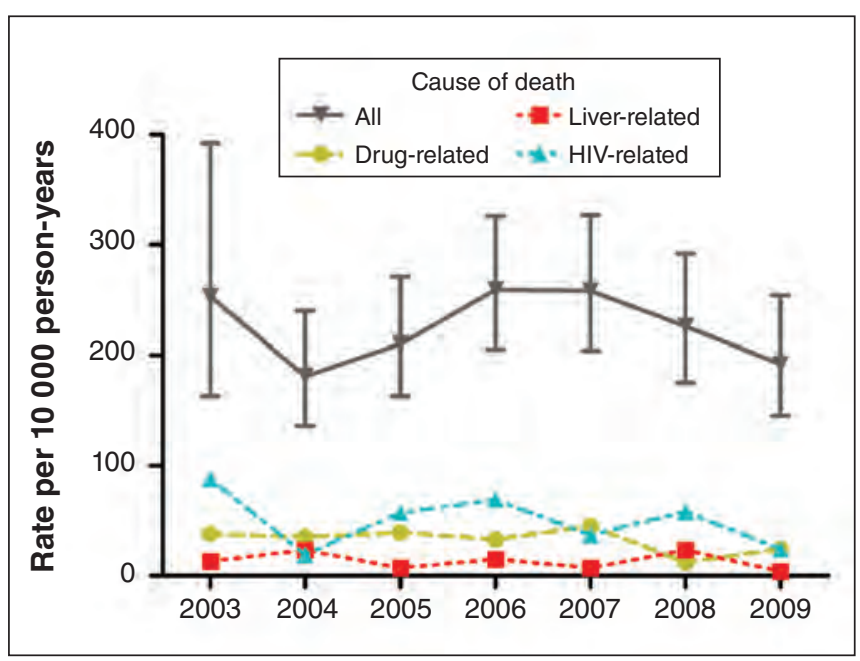

Figure 2: Mortality in the inner-city cohort, by year of follow-up. Drug-, liver- and HIV-related deaths are defined in Methods. Error bars = $95 \%$ confidence intervals. 


\section{Limitations}

This study has several limitations. Because the marginalized, hard-to-reach population under study did not allow for randomized sampling, the sample cannot be considered representative, ${ }^{11}$ as in other studies with similar populations. ${ }^{31}$ However, the sampling measures used ensured a broad reach and inclusion of participants and provided the highest possible degree of representativeness under real-life circumstances. Participation bias related to illicit activities or status in the study population may also be an issue, ${ }^{11}$ although this bias is also found in general population surveys. ${ }^{32}$ The study relied on participants' self-report for some data elements (e.g., history of drug use), the validity of which cannot be formally ascertained. However, self-reported data in similar studies have been shown to be sufficiently valid..$^{33}$ This is an observational cohort study, and no conclusions should be drawn with regard to causality given the possibility of unmeasured confounding variables. Data regarding HCV and HIV infection in this cohort were derived from tests ordered for clinical indications; systematic testing was not performed. HCV status was unknown for $17 \%$ of the participants and HIV status for $22 \%$; however, their demographic characteristics and rates of death were similar to those for participants who had neither HCV nor HIV infection. Participants with positive HCV test results but no linked HIV test results were considered negative for $\mathrm{HIV}$, and those with positive HIV and unknown HCV were classified as HCV negative; although the baseline characteristics between the negative and unknown groups were similar in these cases, some HCV/HIV co-infected individuals may have been misclassified and mortality overestimated in the monoinfected groups. Linked HCV test results did not always include HCV RNA results, and spontaneous clearance may have occurred among some of those with presumed HCV infection, which led to an underestimation of the observed overall effect of HCV infection on mortality. Although the linked mortality records capture all deaths reported in the province of British Columbia, any deaths that went unreported or that occurred in other jurisdictions would lead to an overestimation of person-years of follow-up and an underestimation of mortality.

\section{Conclusion}

Our study showed high mortality in this inner-city population, particularly when compared with the general population of Vancouver. Excess mortality was highest among women, younger participants and those infected with HCV or HIV or both. The significant excess mortality and the leading causes of death observed in this study confirm the need for comprehensive, multidisciplinary services to support this high-risk population and optimize health outcomes, particularly among youth and women. Screening, follow-up and appropriate treatment for HIV and HCV infection are clearly important tools to reduce the risk of HIV-related mortality and transmission and to prevent HCV-related health sequelae. Measures such as mental health care, improved access to housing and harm reduction services are also important to address the drug-related deaths. Every interaction with the health care system can provide an opportunity to engage members of this inner-city population in the types of comprehensive care needed to address their diverse health conditions. Further investment in programs to improve inner-city health care (e.g., HIV, HCV, mental health and addiction services) may help to address the considerable morbidity and mortality in this inner-city population.

\section{References}

1. 2005/6 Downtown Eastside community monitoring report. 10th ed. Vancouver (BC): City of Vancouver; 2007.

2. Miller CL, Kerr T, Strathdee SA, et al. Factors associated with premature mortality among young injection drug users in Vancouver. Harm Reduct 7 2007;4:1.

3. Strathdee SA, Patrick DM, Currie SL, et al. Needle exchange is not enough: lessons from the Vancouver injecting drug use study. AIDS 1997;11:F59-65.

4. Wood E, Kerr T, Spittal PM, et al. The health care and fiscal costs of the illicit drug use epidemic: the impact of conventional drug control strategies. B C Med 7 2003;45:128-34.

5. Wood E, Tyndall MW, Montaner JS, et al. Summary of findings from the evaluation of a pilot medically supervised safer injecting facility. CMA7 2006;175: $1399-404$

6. Kerr T, Small W, Buchner C, et al. Syringe sharing and HIV incidence among injection drug users and increased access to sterile syringes. Am 7 Public Health 2010;100:1449-53.

7. Spittal PM, Hogg RS, Li K, et al. Drastic elevations in mortality among female injection drug users in a Canadian setting. AIDS Care 2006;18:101-8.

8. Tyndall MW, Craib KJ, Currie S, et al. Impact of HIV infection on mortality in a cohort of injection drug users. F Acquir Immune Defic Syndr 2001;28:351-7.

9. Drug situation in Vancouver. Vancouver (BC): Urban Health Research Institute of the British Columbia Centre for Excellence in HIV/AIDS; 2009. Available: http://uhri.cfenet.ubc.ca/images/Documents/dsiv2009.pdf (accessed 2012 July 24).

10. Selected vital statistics and bealth status indicators: one bundred and thirty-ninth annual report 2010. Vancouver (BC): British Columbia Vital Statistics Agency; 2010. Available: www.vs.gov.bc.ca/stats/annual/2010/pdf/ann2010.pdf (accessed 2012 July 18).

11. Magnani R, Sabin K, Saidel T, et al. Review of sampling hard-to-reach and hidden populations for HIV surveillance. AIDS 2005;19(Suppl 2):S67-72.

12. Community Health and Safety Evaluation (CHASE) project: final report. Vancouver (BC): Vancouver Coastal Health Authority, CHASE Project Team; 2005. Available: http://chase.hivnet.ubc.ca/project/pubdocs/CHASE_Reports/CHASE _Final_Report.pdf (accessed 2012 July 2).

13. Evans JL, Tsui JI, Hahn JA, et al. Mortality among young injection drug users in San Francisco: a 10-year follow-up of the UFO study. Am 7 Epidemiol 2012; 175:302-8.

14. Solomon SS, Celentano DD, Srikrishnan AK, et al. Mortality among injection drug users in Chennai, India (2005-2008). AIDS 2009;23:997-1004.

15. Hulse GK, English DR, Milne E, et al. The quantification of mortality resulting from the regular use of illicit opiates. Addiction 1999;94:221-9.

16. Gibson A, Randall D, Degenhardt L. The increasing mortality burden of liver disease among opioid-dependent people: cohort study. Addiction 2011;106: 2186-92.

17. Cornish R, Macleod J, Strang J, et al. Risk of death during and after opiate substitution treatment in primary care: prospective observational study in UK General Practice Research Database. BM7 2010;341:c5475.

18. Degenhardt L, Bucello C, Mathers B, et al. Mortality among regular or dependent users of heroin and other opioids: a systematic review and meta-analysis of cohort studies. Addiction 2011;106:32-51.

19. Degenhardt L, Hall W, Warner-Smith M. Using cohort studies to estimate mortality among injecting drug users that is not attributable to AIDS. Sex Transm Infect 2006;82(Suppl 3):iii56-63

20. Degenhardt L, Singleton J, Calabria B, et al. Mortality among cocaine users: a systematic review of cohort studies. Drug Alcohol Depend 2011;113:88-95.

21. Ferreros I, Lumbreras B, Hurtado I, et al. The shifting pattern of cause-specific mortality in a cohort of human immunodeficiency virus-infected and noninfected injecting drug users. Addiction 2008;103:651-9.

22. O'Kelly FD, O'Kelly CM. The natural history of injecting drug use: a 25-year longitudinal study of a cohort of injecting drug users in inner city Dublin. Ir 7 Med Sci 2012;181:541-8.

23. Bargagli AM, Sperati A, Davoli M, et al. Mortality among problem drug users in Rome: an 18-year follow-up study, 1980-97. Addiction 2001;96:1455-63.

24. Boschini A, Smacchia C, Di Fine M, et al. Community-acquired pneumonia in a cohort of former injection drug users with and without human immunodeficiency virus infection: incidence, etiologies, and clinical aspects. Clin Infect Dis 1996;23:107-13

25. Palepu A, Tyndall MW, Leon H, et al. Hospital utilization and costs in a cohort of injection drug users. CMA7 2001;165:415-20.

26. O'Donnell AE, Pappas L. Pulmonary complications of intravenous drug abuse. Experience at an inner-city hospital. Chest 1988;94:251-3. 
27. Bird SM, Hutchinson SJ, Goldberg DJ. Drug-related deaths by region, sex, and age group per 100 injecting drug users in Scotland, 2000-01. Lancet 2003;362: 941-4.

28. Copeland L, Budd J, Robertson JR, et al. Changing patterns in causes of death in a cohort of injecting drug users, 1980-2001. Arch Intern Med 2004;164:1214-20.

29. Walter SR, Thein HH, Amin J, et al. Trends in mortality after diagnosis of hepatitis B or C infection: 1992-2006. F Hepatol 2011;54:879-86.

30. Grebely J, Raffa JD, Lai C, et al. Impact of hepatitis C virus infection on allcause and liver-related mortality in a large community-based cohort of inner city residents. F Viral Hepat 2011;18:32-41.

31. Craib KJ, Spittal PM, Wood E, et al. Risk factors for elevated HIV incidence among Aboriginal injection drug users in Vancouver. CMA7 2003;168:19-24.

32. Shield KD, Rehm J. Difficulties with telephone-based surveys on alcohol consumption in high-income countries: the Canadian example. Int 7 Methods Psychiatr Res 2012;21:17-28.

33. Darke S. Self-report among injecting drug users: a review. Drug Alcohol Depend 1998;51:253-63.

Competing interests: Mel Krajden has received research grants, paid to his institution, from Merck, Roche, Siemens and Gen-Probe (Hologic). Gregory Dore is a member of advisory boards for Roche, Merck, Gilead, Bristol-Myers Squibb, AbbVie and Janssen; he has received research grants, paid to his institution, from Roche, Merck, Gilead, Bristol-Myers Squibb and AbbVie, and he has received payment for expert testimony from Janssen, speaker fees from Roche and Merck, and travel assistance from Roche, Merck and Gilead. Jason Grebely is a member of the advisory board for Merck; he has received speaker fees from Roche and owns stocks in Gilead; and he has received a research grant, paid to his institution, from Merck. No competing interests declared by the other authors.

Affiliations: From the Division of Infectious Diseases (Deans), Department of Medicine, University of British Columbia, Vancouver, BC; the Department of Statistics and Actuarial Science (Raffa), University of Waterloo, Waterloo, Ont.; the British Columbia Centre for Excellence in HIV/AIDS
(Lai), St. Paul's Hospital, Vancouver, BC; the Centre for Applied Research in Mental Health and Addiction (Fischer), Faculty of Health Sciences, Simon Fraser University, Burnaby, BC; the British Columbia Centre for Disease Control (Krajden), Vancouver, BC; The Kirby Institute for infection and immunity in society (Amin, Dore, Grebely), University of New South Wales, Sydney, Australia; the Centre for Health Systems and Safety Research (Walter), Australian Institute of Health Innovation, University of New South Wales, Sydney, Australia; and the Division of Infectious Diseases, Department of Medicine (Tyndall), University of Ottawa, Ottawa, Ont.

Contributors: Jason Grebely and Mark Tyndall contributed equally to this work. Calvin Lai and Mark Tyndall designed the original study and wrote the protocol. Gregory Deans, Jesse Raffa, Jason Grebely and Mark Tyndall designed the mortality substudy. Gregory Deans, Jesse Raffa and Jason Grebely drafted the primary statistical analysis plan, which was reviewed by Calvin Lai, Benedikt Fischer, Mel Krajden, Janaki Amin, Scott Walter and Gregory Dore. The primary statistical analysis was conducted by Gregory Deans and was reviewed by all of the coauthors. All of the authors reviewed the data analysis. Gregory Deans wrote the first draft of the manuscript. All of the authors critically revised the manuscript and approved the final version submitted for publication.

Funding: The Community Health and Safety Evaluation cohort was established with funding from the Vancouver Coastal Health Authority. Gregory Deans was supported by funding from the National Canadian Research and Training Program in Hepatitis C. Gregory Dore is supported by a National Health and Medical Research Council Practitioner Research Fellowship. Jason Grebely is supported by a National Health and Medical Research Council Career Development Fellowship.

Supplemental information: For reviewer comments and the original submission of this manuscript, please see www.cmajopen.ca/content /1/2/E68/suppl/DC1 